\title{
Immunological Response to ChAdOx1 nCoV-19 Vaccine among Health Care Workers at a Tertiary Care Hospital in Chennai
}

\author{
P. Sneka (D), K.P. Hamsadwani* (D) and V. Sangamithra \\ Department of Microbiology, Bhaarath Medical College and Hospital, Chennai - 600 073, Tamil Nadu, India.
}

\begin{abstract}
ChAdOx1 nCoV-19 Vaccine (Covishield) has shown good efficacy data but the presence of non responders to the vaccine and the duration of protection conferred by the vaccine has not been clearly documented. To study the immunological response to ChAdOx1 nCoV-19 Vaccine among Health Care workers (HCWs) at a tertiary care hospital in Chennai. Materials and Methods: A Prospective study was conducted to analyze the duration of protection conferred by ChAdOx1 nCoV-19 Vaccine by testing the serum samples for Anti SARS IgG Antibody to spike protein by EUROIMMUNE ELISA Kit protocol by testing the pre vaccine sample, samples 2 weeks and 4 weeks following 1st dose, 3 months and 6 months post 2 doses of vaccination and to study the association of waning immune response with comorbidities. A total of 265 Health Care Workers (HCWs) involving Nurses (35\%), Doctors (32\%), Technical staffs (17\%) and House keeping staffs (16\%) were included in the study. Majority were in age group of $41-50$ Years (33\%). Associated comorbidity was noticed in $19 \%$ of HCWs. All $100 \%$ had sero conversion 4 weeks following Covishield but only $88 \%$ had sero conversion 2 weeks following the 1st dose of Covishield. $100 \%$ of the HCWs had detectable levels of Anti SARS IgG antibody to spike protein 3 months following 2 nd dose of Covishield but 6 months post 2nd dose only $90.5 \%$ detectable levels of Anti SARS IgG antibody to spike protein. Among the $9.5 \%$ with waning immune response $68 \%$ had associated comorbidity like obesity (47\%), Diabetes Mellitus (41\%), Hyperlipidemia (6\%) and Chronic lung disease (6\%). It is important to maintain the protective antibody titers by vaccinating all the individuals with booster dose of the vaccine and considering population with comorbidities a high risk group for early priority.

Keywords: ChAdOx1, ELISA, Vaccine, Anti SARS
\end{abstract}

*Correspondence: hamsuashok@gmail.com;+91 9884481434

(Received: January 1, 2022; accepted: January 27, 2022)

Citation: Sneka P, Hamsadwani KP, Sangamithra V. Immunological Response to ChAdOx1 nCoV-19 Vaccine among Health Care Workers at a Tertiary Care Hospital in Chennai. J Pure Appl Microbiol. 2022;16(1):578-584. doi: 10.22207/JPAM.16.1.56

(c) The Author(s) 2022. Open Access. This article is distributed under the terms of the Creative Commons Attribution 4.0 International License which permits unrestricted use, sharing, distribution, and reproduction in any medium, provided you give appropriate credit to the original author(s) and the source, provide a link to the Creative Commons license, and indicate if changes were made. 


\section{INTRODUCTION}

Ever since the origin of the first case of Novel coronavirus also called SARS-CoV was noticed in China the virus has spread to over 200 countries marking it a global pandemic which has caused loss of numerous lives and livelihood. ${ }^{1}$ Vaccines are an efficient and economical interventions the mankind had ever invented. The only ray of hope to control the Global pandemic is vaccinating all the population to achieve a suitable level of herd immunity. ${ }^{2}$ Studies suggest to prevent the spread of the disease and to curtail the pandemic it is essential to achieve an acquired immunity of $67 \% .^{3,4}$ WHO has placed HCWs as the high priority group for COVID-19 vaccines. Hence it is mandatory to vaccinate all HCWs to protect themselves as well as the patients from the disease. ${ }^{5}$ India began its vaccination campaign for COVID-19 on 16 January 2021. Currently, the country has approved three COVID-19 vaccines namely

1. Covishield (ChAdOx1- Serum institute of India)- 70-90\%

2. Covaxin (BBV152 -Bharath Biotech)- 78-95\%

3. Sputnik V (Gam-COVID-Vac; Gamaleya Research Institute of Epidemiology and Microbiology.)- $91 \%{ }^{6}$

'The approved COVID-19 vaccines in India were all manufactured in a rush owning to the rapid need to curtail the pandemic. Though these vaccines have obtained EUA (Emergency Use Authorization) and have good efficacy data there is no clear evidence of non responders to the COVID-19 vaccines and the duration of immunity conferred by these vaccines". Despite Mass vaccination campaigns there has been consistent increase in the number of COVID-19 cases reported. ${ }^{7}$ Thus, in this research immunological response to COVID-19 vaccines among Health Care workers (HCWs) at a tertiary care hospital in Chennai was studied.

\section{Objectives of the study}

1. To detect the pre vaccination antibody titre

2. To determine the sero conversion rate following COVID-19 vaccines and the presence of non responders to the COVID-19 vaccines.

3. To follow up for the persistence of neutralizing antibodies 3 months \& 6 months post vaccination and analyze the need for the $3 r d$ booster dose

\section{MATERIALS AND METHODS}

Study type : Prospective pilot study

Study group : Health care workers

Study duration : One year

Sample size : 265

\section{Inclusion criteria}

All Health care workers who have not received COVID-19 vaccines.

\section{Exclusion criteria}

Health care workers with $\mathrm{H} / \mathrm{O}$ prior COVID-19 vaccination or $\mathrm{H} / \mathrm{O}$ prior symptomatic COVID-19 disease.

The study was conducted after obtaining approval from the Institution ethics committee (Ethical No: BIEC-02-21) and consent from all the study participants. A detailed $\mathrm{H} / \mathrm{O}$ was obtained from the study population for presence of associated comorbidities.

\section{Procedure}

Under aseptic precautions $2 \mathrm{ml}$ of venous blood was collected and serum was separated and stored at 4 degree until further processing. Further analysis was done for detecting Anti SARS IgG Antibody to spike protein by Semi quantitative ELISA by EURO IMMUNE ANTI SARS-CoV-2 Human IgG ELISA KIT targeting spike protein approved by ICMR as per the kit protocol.

- The blood samples were collected in $5 \mathrm{ml}$ SST (Serum separation tubes) vacutainer tubes from all the study participants before vaccination. The samples were analyzed for the IgG antibody to spike protein. These samples were used to know the prevalence of herd immunity among the study population by asymptomatic COVID.

- Blood samples were collected 2 weeks and 4 weeks following first dose of Covishield and checked for seroconversion by looking for the significant levels of IgG antibody to spike protein and also to detect if there were non responders to the vaccine.

Eurolmmun's FDA EUA-approved SARSCoV-2 IgG ELISA for serum (catalog no. El 26069620, Eurolmmun, NJ, USA) targeting spike (S) protein was run according to the manufacturerprovided protocol manually. Data were then 
analyzed as recommended by the manufacturer and results reported as a ratio (equation 1 ). Specimens whose ratio exceeded or was equal to 1.1 were considered positive, while specimens with a ratio greater than 0.8 and less than 1.1 were considered equivocal and specimens with a ratio less than or equal to 0.8 were considered negative. Specimens with ratios in the equivocal range were recommended to be rerun, but this did not apply to any specimens in this study.

Determination of specimen-to-cutoff ratio ( $\mathrm{S} / \mathrm{CO}$ ratio) as defined by the manufacturer by dividing specimen OD by the average OD of the calibrators was performed using equation 1 as follows:

$\underline{\text { Extinction of the control or patient's sample }}=$ Ratio Extinction of calibrator

- 3 months and 6 months post 2 doses of Covishield the blood samples were again

Table 1. Age wise distribution of the study population collected to look for the maintenance of protective levels of IgG antibody. These samples collected post vaccination will help us to know the duration of protection conferred by Covishield and might help us in evaluating the need for a booster dose and timing of the booster dose of the vaccine.

\section{RESULTS}

We included a total of 265 Health care workers (HCW) which includes Doctors, Nurses, Technical staffs and House keeping staffs. The distribution of the study population is shown in Fig. 1.

The maximum number of our study population was in the age group of 41-50 years. Age wise distribution of the study population is shown in Table 1.

Distribution of HCWs with/without comorbidities is shown in Fig. 2.

\begin{tabular}{lccccc}
\hline $\begin{array}{l}\text { Age Range } \\
\text { in yrs }\end{array}$ & $\begin{array}{c}\text { Doctors } \\
(n=85)\end{array}$ & $\begin{array}{c}\text { Nurses } \\
(n=92)\end{array}$ & $\begin{array}{c}\text { Technical } \\
\text { Staffs } \\
(n=46)\end{array}$ & $\begin{array}{c}\text { Housekeeping } \\
\text { staffs } \\
(n=42)\end{array}$ & $\begin{array}{c}\text { Total } \\
(n=265)\end{array}$ \\
\hline $20-30$ & 12 & 28 & 18 & 08 & $66(28 \%)$ \\
$31-40$ & 33 & 39 & 17 & 15 & $104(27 \%)$ \\
$41-50$ & 32 & 22 & 08 & 17 & $79(33 \%)$ \\
$51-60$ & 08 & 04 & 03 & 02 & $17(12 \%)$ \\
\hline
\end{tabular}

Mean age of the population is 36 years. And most of the healthcare workers lie in 31-40 years of interval.

\section{DOCTORS \\ NURSES TECHNICAL STAFF \\ HOUSEKEEPING}

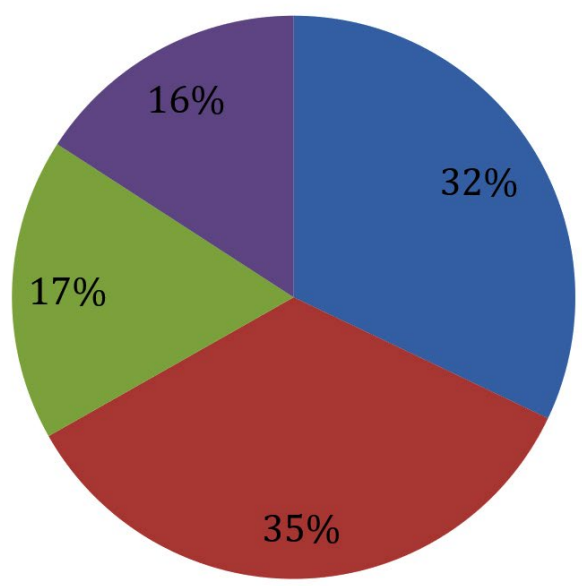

Fig. 1. Distribution of Study Population. 
Distribution of comorbidities among the different HCWs in shown in Table 2.

$100 \%$ of the HCWs had sero conversion 4 weeks following the 1st dose of Covishield but only $88 \%$ had sero conversion 2 weeks following the 1st dose of Covishield. Sero conversion rate following Covishield is shown in Fig. 3. Which is significant with $\mathrm{p}$-value $<0.05$.

3 Months following the 2 doses of Covishield $100 \%$ had protective antibody titers but 6 months later only $90.5 \%$ showed protective antibody titre. Post vaccination antibody status following 2 doses is shown in Fig. 4 which is significant with $p$-value $<0.05$ i.e., 0.03

Immune response post vaccination and association of waning immune response to comorbidity among the study groups is shown in Table 3.

Our study participants with Diabetes Mellitus, Obesity, Hyperlipidemia and Chronic lung disease showed waning of antibody titers. Association of various comorbidities with waning immune response is shown in Table 4.

Waning Immune response in study groups with/without co-morbidities is shown in Fig. 5.

There is significant association between waning immune response with comorbidity when compared with healthcare workers with p-value<0.05 i.e., 0.003 .

Among the study group with associated comorbidity Obesity, Diabetes Mellitus, Hyperlipidemia and chronic lung disease was

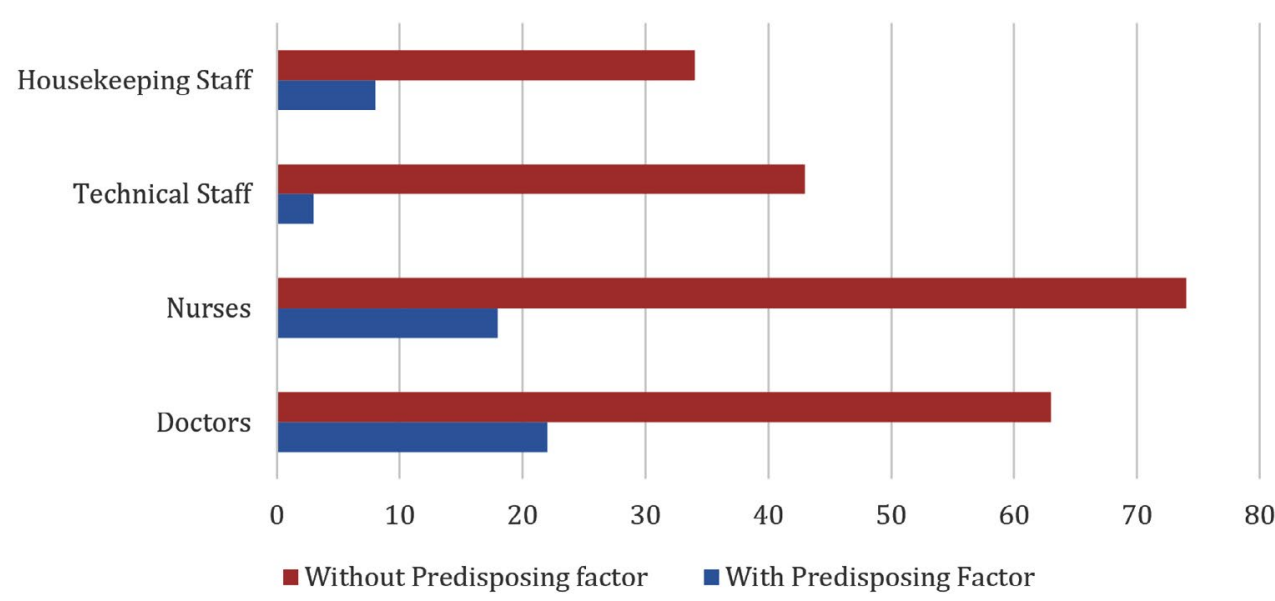

Fig. 2. Distribution of HCWs with/without comorbidities.

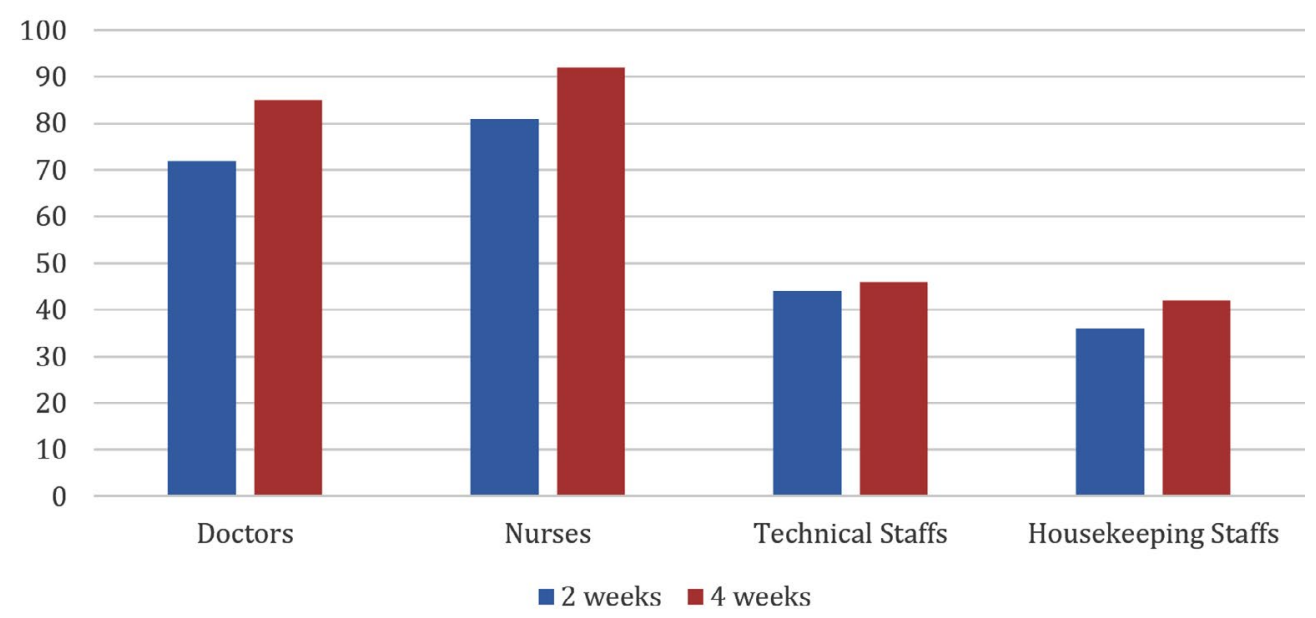

Fig. 3. Sero conversion rate following the Covishield. 
associated with waning antibody titres. Distribution of Comorbidities in the study group with waning immunity is shown in Fig. 6.

\section{DISCUSSION}

The study was conducted among 265 Health care workers to evaluate the immunological response to COVID-19 Vaccines. In our study group

Table 2. Distribution of comorbidities among different HCWs

\begin{tabular}{lcccc}
\hline Comorbidities & $\begin{array}{c}\text { Doctors } \\
(n=22) 26 \%\end{array}$ & $\begin{array}{c}\text { Nurses } \\
(n=18) 19.5 \%\end{array}$ & $\begin{array}{c}\text { Technical } \\
\text { staffs }(n=3) 6.5 \%\end{array}$ & $\begin{array}{c}\text { Housekeeping } \\
\text { staff }(n=8) 19 \%\end{array}$ \\
\hline Diabetes mellitus & $5(23 \%)$ & $5(28 \%)$ & $1(33.3 \%)$ & $2(25 \%)$ \\
Hypertension & $2(9 \%)$ & $1(5.5 \%)$ & - & $1(12.5 \%)$ \\
Cardiac Diseases & $4(! 8 \%)$ & $1(5.5 \%)$ & - & - \\
Obesity & $7(32 \%)$ & $4(22 \%)$ & $1(33.3 \%)$ & $3(37.5 \%)$ \\
Chronic Lung Disease & - & $2(11 \%)$ & $1(33.3 \%)$ & $1(12.5 \%)$ \\
Hyperlipidemia & - & $3(17 \%)$ & - & - \\
$>1$ co-morbid condition & $4(18 \%)$ & $2(11 \%)$ & - & $1(12.5 \%)$ \\
\hline
\end{tabular}

Table 3. Immune response post vaccination and association of waning immune response to comorbidity

\begin{tabular}{|c|c|c|c|c|c|c|c|}
\hline \multicolumn{2}{|c|}{$\begin{array}{l}\text { Doctors } \\
(n=85)\end{array}$} & \multicolumn{2}{|c|}{$\begin{array}{l}\text { Nurses } \\
(n=85)\end{array}$} & \multicolumn{2}{|c|}{$\begin{array}{l}\text { Technical staffs } \\
\qquad(n=46)\end{array}$} & \multicolumn{2}{|c|}{$\begin{array}{l}\text { House keeping staffs } \\
\qquad(n=42)\end{array}$} \\
\hline 3 Months & 6 Months & 3 Months & 6 Months & 3 Months & 6 Months & 3 Months & 6 Months \\
\hline $85(100 \%)$ & $76(89 \%)$ & $92(100 \%)$ & $84(91 \%)$ & $46(100 \%)$ & $41(89 \%)$ & $42(100 \%)$ & $39(76 \%)$ \\
\hline \multicolumn{8}{|c|}{ Waning immune response $(n=25) 9.5 \%$} \\
\hline \multicolumn{2}{|c|}{$\begin{array}{l}\text { Doctors } \\
(n=9)\end{array}$} & \multicolumn{2}{|c|}{$\begin{array}{l}\text { Nurses } \\
(n=8)\end{array}$} & \multicolumn{2}{|c|}{$\begin{array}{l}\text { Technical staffs } \\
\quad(n=5)\end{array}$} & \multicolumn{2}{|c|}{$\begin{array}{l}\text { House keeping staffs } \\
\qquad(n=3)\end{array}$} \\
\hline $\begin{array}{l}\text { Presence of } \\
\text { Associated } \\
\text { comorbidity }\end{array}$ & $\begin{array}{c}\text { No } \\
\text { Associated } \\
\text { comorbidity }\end{array}$ & $\begin{array}{l}\text { Presence of } \\
\text { Associated } \\
\text { comorbidity }\end{array}$ & $\begin{array}{c}\text { No } \\
\text { Associated }\end{array}$ & $\begin{array}{c}\text { Presence of } \\
\text { Associated } \\
\text { comorbidity }\end{array}$ & $\begin{array}{c}\text { No } \\
\text { Associated } \\
\text { comorbidity }\end{array}$ & $\begin{array}{c}\text { Presence of } \\
\text { Associated } \\
\text { comorbidity }\end{array}$ & $\begin{array}{c}\text { No } \\
\text { Associated } \\
\text { comorbidity }\end{array}$ \\
\hline $7(78 \%)$ & $2(22 \%)$ & $5(62.5 \%)$ & $3(37.5 \%)$ & $2(40 \%)$ & $3(60 \%)$ & $3(100 \%)$ & $0(0 \%)$ \\
\hline
\end{tabular}

There is significant association between presence of associated comorbidity and health care workers with $p$-value $<0.05$ i.e., 0.04 .

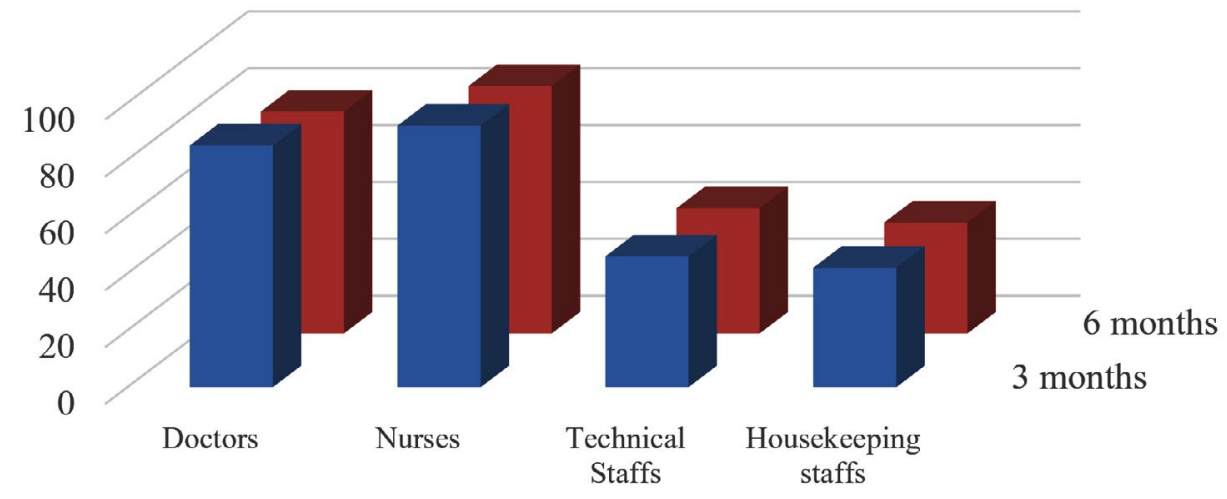

\section{3 months $\quad 6$ months}

Fig. 4. Post vaccination Antibody status following 2 doses of Covishield. 


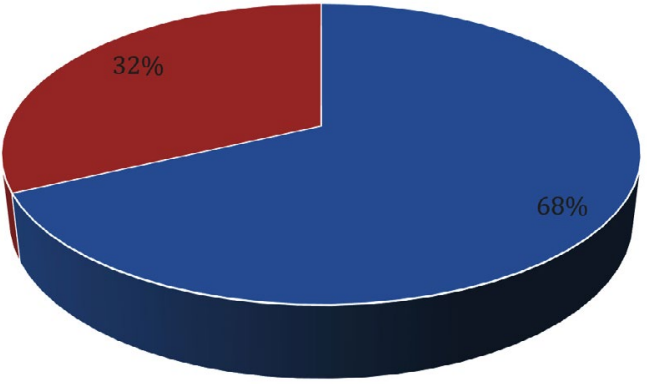

- With Co morbidities - Without Comorbidities

Fig. 5. Waning Immune response in study groups with/ without co-morbidities.

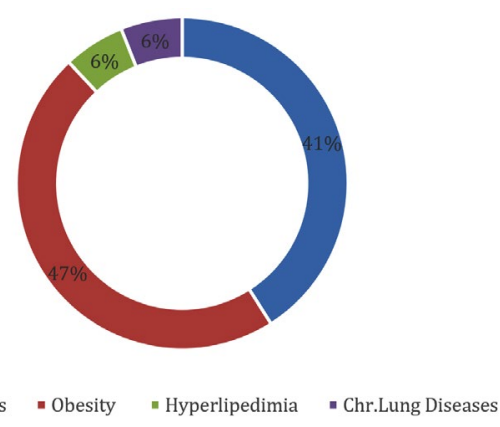

Fig. 6. Distribution of Comorbidities in the study group with waning immunity.

Table 4. Association of various comorbidities with waning Immune response

\begin{tabular}{|c|c|c|c|}
\hline $\begin{array}{l}\text { Doctors } \\
(n=7)\end{array}$ & $\begin{array}{c}\text { Nurses } \\
(n=5)\end{array}$ & $\begin{array}{l}\text { Technical staff } \\
\qquad(n=2)\end{array}$ & $\begin{array}{l}\text { Housekeeping staff } \\
\qquad(n=3)\end{array}$ \\
\hline $\begin{array}{l}\text { Diabetes } \\
\text { mellitus (3) }\end{array}$ & $\begin{array}{l}\text { Diabetes mellitus (2) } \\
\text { Diabetes mellitus (1) } \\
\text { Diabetes mellitus (1) }\end{array}$ & & \\
\hline Obesity (4) & $\begin{array}{l}\text { Hyperlipidemia (1) } \\
\text { Obesity(1) } \\
\text { Chronic lung } \\
\text { disease (1) }\end{array}$ & Obesity (1) & Obesity (2) \\
\hline
\end{tabular}

majority were Nurses (35\%) followed by Doctors (32\%), Technical staffs (17\%) and House keeping staffs (16\%). The enrolled study participants were evaluated for comorbidities like Diabetes mellitus, Hypertension, Hyperlipidemia, Pre existing cardiac diseases, assessed for obesity, chronic lung diseases through detailed history and laboratory assessment. We found that $10 \%$ of the study population had protective levels of Anti SARS IgG Antibody to Spike protein before receiving COVID-19 vaccines indicating the acquired immunity due to aymptomatic infection. We found $100 \%$ sero conversion rate 4 weeks following the 1st dose of Covishield but 2 weeks following the 1st dose of the vaccine only $88 \%$ had protective titers. We also found there were no non responders to Covishield which is in contrast to other studies which showed the presence of non responders in persons with Immune Mediated Inflammatory Disease (IMID) and persons with hematological malignancies. $^{8,9}$
In our study, we found $9.5 \%$ of the study participants did not have protective antibody titers 6 months following 2 doses of Covishield. Other studies have also documented waning immunity following 2 doses of COVID-19 vaccines they have not clearly stated the duration after which immune waning occurs. ${ }^{10,11}$ Among the study group with waning antibody titres, $68 \%$ had associated one or the other comorbidity and the remaining $32 \%$ had no associated co morbidity. Various studies have documented the association of disease severity with comorbidities but data on the immune protection offered by COVID vaccines to comorbidities is lacking. ${ }^{12,13}$ Among the different comorbidities in the immune response waning group Obesity (47\%) followed by Diabetes mellitus (41\%) were the major contributors followed by Hyperlipidemia (6\%) and Chronic lung disease (6\%). Studies done in other parts of the world also revealed presence of associated comorbidities causes waning immune response for COVID-19 vaccines. $^{14}$ 


\section{CONCLUSION}

The study highlights the importance to consider booster doses to be given 6 months following 2 doses of Covishield for all individuals with pre existing comorbidities as high risk group to prevent the risk of Reinfection and overcome the pandemic.

\section{ACKNOWLEDGMENTS}

None.

\section{CONFLICT OF INTEREST}

The authors declare that there is no conflict of interest.

\section{AUTHORS' CONTRIBUTION}

All authors listed have made a substantial, direct and intellectual contribution to the work, and approved it for publication.

\section{FUNDING}

None.

\section{DATA AVAILABILITY}

All data sets generated or analyzed during the study are included in the manuscript.

\section{ETHICS STATEMENT}

The study was conducted after approval from the Bhaarath Institutional Ethics committee, India (Ethical No: BIEC-02-21)

\section{INFORMED CONSENT}

The study was conducted after obtaining informed consent from all the participants.

\section{REFERENCES}

1. WHO. Coronavirus disease 2019 (COVID-19) Situation Report -26. Beijing (2020). Available online at: http://www.nhc.gov.cn/xcs/yqtb/list_gzbd.shtml

2. Frederiksen LSF, Zhang $Y$, Foged $C$, Thakur A. The long road toward COVID-19 herd immunity: vaccine platform technologies and mass immunization strategies. Front Immunol. 2020;11:1817. doi: 10.3389/fimmu.2020.01817

3. Randolph HE, Barreiro LB. Herd immunity: understanding COVID-19. Immunity. 2020;52(5):737741. doi: 10.1016/j.immuni.2020.04.012

4. Fontanet A, Cauchemez S. COVID-19 herd immunity: where are we? Nat Rev Immunol. 2020;20(10):583584. doi: 10.1038/s41577-020-00451-5

5. Wang J, Jing R, Lai X, et al. Acceptance of COVID-19 vaccination during the COVID-19 pandemic in China. Vaccines. 2020;8(3):482. doi: 10.3390/ vaccines 8030482

6. Choudhary OP, Choudhary P, Singh I. India's COVID-19 vaccination drive: key challenges and resolutions. Lancet Infect Dis. 2021;21(11):1483-1484. doi: 10.1016/S1473-3099(21)00567

7. Subramanian SV. India faces a challenge with its mass vaccination efforts. Lancet Glob Health. 2021;9(9):e1201-e1202. doi: 10.1016/S2214109X(21)00260-6

8. Simon D, Tascilar K, Fagni F, et al. Efficacy and safety of SARS-CoV-2 revaccination in non-responders with immune-mediated inflammatory disease Annals of the Rheumatic Diseases. 2021:1-5. doi: 10.1136/ annrheumdis-2021-221554

9. Teh JSK, Coussement J, Neoh ZCF, et al .Immunogenicity of COVID-19 vaccines in patients with haematological malignancy: A systematic review and meta-analysis. medRxiv. 2021. doi: 10.1101/2021.11.06.21265967

10. Khoury DS, Cromer D, Reynaldi A, et al. Neutralizing antibody levels are highly predictive of immune protection from symptomatic SARS-CoV-2 infection. Nat Med 27, 1205-1211 (2021). doi: 10.1038/s41591 $-021-01377-8$

11. Borges do Nascimento IJ, Marusic A, Cacic N, et al. Novel Coronavirus Infection (COVID-19) in humans: a scoping review and meta-analysis. J Clin Med. 2020;9:941. doi: $10.2139 /$ ssrn.3550028

12. Emami A, Javanmardi F, Pirbonyeh N, Akbari A. Prevalence of Underlying Diseases in Hospitalized Patients with COVID-19: a Systematic Review and MetaAnalysis. Arch Acad Emerg Med. 2020;24;8(1):e35. PMCID: PMC7096724.

13. Yang J, Zheng $Y$, Gou X, et al. Prevalence of comorbidities in the novel Wuhan coronavirus (COVID-19) infection: a systematic review and meta-analysis. Int I Infect Dis. 2020;94:91-95. doi: 10.1016/j.ijid.2020.03.017

14. Nomura Y, Sawahata M, Nakamura Y, et al. Attenuation of antibody titers during 3-6 months after the second dose of the BNT162b2 vaccine depends on sex, with age and smoking as risk factors for lower antibody titers at 6 months. medRxiv. 2021. doi: 10.1101/2021.11.14.21266334 